\title{
SISTEM INFORMASI PROMOSI DAN PENJUALAN KERAJINAN SULAMAN BERBASIS WEB PADA SULAMAN INDAH MAYANG PARIAMAN
}

\author{
Nelfira ${ }^{1}$, Nency Extise Putri ${ }^{2}$, Via Rahmai Yuni ${ }^{3}$ \\ STMIK Indonesia Padang ${ }^{1,2,3}$ \\ nelfira@stmikindonesia.ac.id ${ }^{1}$, nencyextiseputri@stmikindonesia.ac.id ${ }^{2}$,viarahmaiyuni@gmail.com ${ }^{3}$ \\ DOI: http://dx.doi.org/10.31869/rtj.v2i2.1329
}

\begin{abstract}
Abstrack: This reseach was conducted at the handycrafts Sulaman Indah Mayang Pariaman. Sulaman Indah Mayang is a bussiness that sells various kinds of minang embroidered crafts. The effort craft Sulaman Indah Mayang still use conventional way in processing sales data and do promotion. For that required an information system that will assist in the process of promotion and sales. Information system application of promotion and sale of web based embroidery craft developed using PHP programming language and MySql as database. Application design using object oriented methodology with UML design tool. The end result of this research is the creation of application of Information System Promotion and Web-Based Sales that can help Sulaman Indah Mayang in the process of promotion and sales.
\end{abstract}

Keywords: Information System, Promotion and Sale, Sulaman Indah Mayang

Abstrak:Penelitian ini dilakukan pada usaha kerajinan Sulaman Indah Mayang Pariaman. Sulaman Indah Mayang merupakan usaha kerajinan yang menjual berbagai macam bentuk hasil kerajinan sulaman minang. Usaha kerajinan Sulaman Indah Mayang masih menggunakan cara konvensional dalam mengolah data penjualan dan melakukan promosi. Untuk itu dibutuhkan sebuah sistem informasi yang akan membantu dalam proses promosi dan penjualan. Aplikasi sistem informasi promosi dan penjualan kerajinan sulaman berbasis web dikembangkan menggunakan bahasa pemrograman PHP dan MySql sebagai basis data. Perancangan aplikasi menggunakan metodologi berorientasi objek dengan alat bantu perancangan UML. Hasil akhir dari penelitian ini adalah terciptanya aplikasi Sistem Informasi Promosi dan Penjualan Berbasis Web yang dapat membantu Sulaman Indah Mayang dalam melakukan proses promosi dan penjualan.

\section{Kata kunci: Sistem Informasi, Promosi dan Penjualan, Sulaman Indah Mayang}

\section{PENDAHULUAN}

Perkembangan teknologi informasi

saat ini telah mendorong perubahan diberbagai segi kehidupan. Salah satu perubahan yang terjadi yaitu pemanfaatan berbagai macam sistem informasi [1]. Penggunaan teknologi komputer dan teknologi komunikasi menghasilkan sebuah penggabungan sistem informasi yang saat ini mudah untuk diakses tanpa adanya batasan waktu. Sistem informasi berguna untuk memberikan suatu penyelesaian berupa informasi yang dapat dipakai untuk mengambil suatu keputusan baik berupa jangka pendek, menengah atau panjang dalam sebuah organisasi.

Banyak industri skala kecil mempromosikan dan menjual produknya terbatas pada daerah tempat usaha itu berada [2]. Hal ini akan menyebabkan produk hanya akan dikenal oleh masyarakat daerah tersebut dan penjualan tidak akan meningkat [3]. Salah satu cara meningkatkan luas daerah pemasaran yaitu dengan menggunakan sistem informasi berbasis web atau online [4] . Dengan memanfaatkan sistem informasi berbasis web produk usaha industri skala kecil dapat disebarkan secara luas mulai dari wilayah regional sampai ke mancanegara. Salah satu produk usaha industri skala kecil yaitu berupa kerajinan rumah tangga dalam bentuk sulaman [5]. Kerajinan sulaman merupakan produk unggulan kota Pariaman [6]. Kerajinan sulaman adalah kerajinan yang bernuansa tradisional yang diperoleh secara turun temurun dari nenek moyang. Proses pembuatan kerajinan ini dilakukan dengan tangan manusia bukan dengan mesin.

Berdasarkan hasil observasi di lapangan, kerajinan sulaman ini dipromosikan melalui mulut ke mulut, pameran-pameran, memposting di media sosial dan media cetak. 
Sistem penjualan kerajinan sulaman ini dilakukan secara langsung pada masyarakat. Pengrajin memajang hasil kerajinan. Proses pembelian dilakukan langsung pada pembeli yang datang ke Sulaman Indah Mayang dan mencari sendiri barang yang diinginkan. Hal ini kurang efisien karena tidak semua pembeli mengetahui keberadaan usaha ini, dan dalam pemilihan barang yang akan dibeli membutuhkan banyak waktu karena pembeli tidak mengetahui posisi barang [7].

Selain itu proses pencatatan laporan penjualan pada Sulaman Indah Mayang masih dilakukan secara manual, yaitu pencatatan pada buku. Hal ini tidak efektif diterapkan untuk jangka panjang, karena pencatatan pada buku memiliki banyak kekurangan. Kekurangannya seperti tidak tercatatnya semua transaksi penjualan, sehingga akan menimbulkan kesenjangan antar pemasukan dan pengeluaran.

$$
\text { Sulaman Indah Mayang }
$$

membutuhkan sebuah sistem informasi promosi dan penjualan kerajinan sulaman berbasis web [8]. Hal ini sangat penting karena keberadaan sistem informasi promosi dan penjualan dapat membantu dalam penyampaian informasi mengenai kerajinan sulaman Pariaman beserta produk secara detail kepada pelanggan dengan cepat melalui internet. Sistem informasi promosi dan penjualan ini dapat dikelola sendiri oleh pemilik. Laporan penjualan akan didapat secara otomatis yang dapat diakses kapanpun dan dimanapun, sehingga memudahkan pemilik dalam mengelola pemasukan dan pengeluaran.

Promosi adalah media untuk mengenalkan suatu produk barang dan jasa yang baru atau produk yang sudah ada sebelumnya. Program distribusi dan penjualan bisa didefinisikan sebagai program yang terdiri atas berbagai kegiatan pemasaran yang berusaha mempelancar dan mempermudah penyampaian barang dari produsen kepada konsumen, sehingga penggunaannya sesuai dengan yang diperlukan berdasarkan jenis, jumlah, harga, tempat, dan saat dibutuhkan [9].

Promosi penjualan (sales promotion) merupakan segala bentuk penawaran atau insentif untuk jangka pendek yang ditujukan bagi pembeli, pengecer atau pedagang grosir dan dirancang untuk memperoleh respon spesifik dan segera. Sistem informasi promosi dan penjualan kerajinan sulaman merupakan suatu sistem yang menghubungkan manusia dan komputer yang digunakan untuk mengenalkan produk dan melakukan transaksi penjualan kerajinan sulaman agar kerajinan sulaman dapat dikenal oleh masyarakat luas [10].

\section{METODE PENELITIAN}

Metode penelitian yang digunakan sebagai berikut [11]:

1. Penelitian Lapangan (Field Research)

Berdasarkan survei dilakukan pada Sulaman Indah Mayang untuk mendapatkan data yang diinginkan dan mengetahui langsung permasalahan. Adapun metode yang digunakan dalam penelitian lapangan ini diantaranya :

a. Observasi (Observation)

Melakukan pengamatan langsung terhadap sistem yang sedang berjalan saat ini, dan melihat barang-barang serta dokumen laporan penjualan pada usaha Sulaman Indah Mayang.

b. Kuisioner (quesioner)

Membuat daftar pertanyaan. Memberikan daftar pertanyaan kepada pimpinan sekaligus pengrajin sulaman yang berhubungan dengan pengolahan data dan laporan penjualan.

c. Wawancara langsung (Interview) Mewawancarai secara langsung setiap personil yang terlibat pada usaha Sulaman Indah Mayang.

2. Penelitian Berorientasi Objek

Adapun langkah-langkah dari metodologi berorientasi objek pada sistem informasi promosi dan penjualan kerajinan sulaman adalah [9] :

a Analisis Berorientasi Objek (Object Oriented Analysis) menganalisis sistem promosi dan penjualan kerajinan sulaman pada Sulaman Indah Mayang Pariaman dengan tujuan untuk mendapatkan informasi tentang permasalahan yang terjadi dan menemukan solusi untuk permasalahan tersebut.

b Desain Berorientasi Objek atau Object Oriented Design (OOD) .Merupakan tahap lanjutan setelah analisis berorientasi

$\begin{array}{lr}\text { Fakultas Teknik UMSB } & \text { ISSN 2599-2081 } \\ & \text { EISSN 2599-2090 }\end{array}$


objek, tujuan sistem diorganisasikan ke dalam sub-sistem berdasar struktur analisis dan arsitektur yang dibutuhkan. Mendesain sistem baru yang dapat menyelesaikan masalah-masalah yang dihadapi pada Sulaman Indah Mayang.

c Pemograman Berorientasi Objek menggunakan bahasa pemograman PHP sebagai bahasa pemograman guna mendukung pemograman berorientasi objek.

d Pengujian Berorientasi Objek mengaplikasikan dan menggunakan sistem informasi promosi dan penjualan yang telah dibuat, dengan melakukan pengujian terlebih dahulu pada sistem tersebut.

\section{HASIL DAN PEMBAHASAN}

Untuk mengatasi masalah yang ada pada kerajinan Sulaman Indah Mayang saat ini dibutuhkan perancangan untuk membangun sistem baru. Use Case Diagram [10] Sistem Informasi Promosi dan Penjualan Sulaman Indah Mayang, adalah seperti dilihat pada Gambar 1.

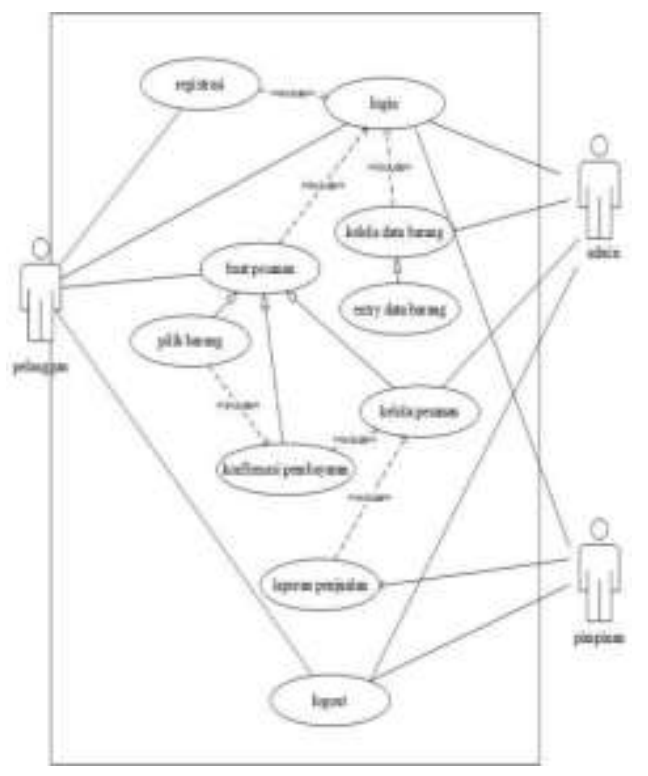

Gambar 1. Use Case Diagram Sistem Informasi Promosi dan Penjualan Sulaman Indah Mayang

Hasil analisis sistem informasi promosi dan penjualan kerajinan sulaman Indah Mayang pada perancangan yang diusulkan adalah: $\begin{array}{lcr}\text { 1. Tersedianya } & \text { website } & \text { untuk } \\ \text { mempromosikan } & \text { hasil kerajinan } \\ \text { sulaman Indah } & \text { Mayang } & \text { kepada }\end{array}$ konsumen atau pelanggan.

2. Data penjualan dapat diketahui langsung oleh pimpinan kerajinan sulaman Indah Mayang, karena pengolahan data keuangan secara komputerisasi.

3. Meningkatkan aktifitas promosi dan penjualan pada kerajinan sulaman Indah Mayang.

Perbedaan hasil analisis sistem yang lama dengan analisis sistem yang baru dapat dilihat pada Tabel 1.

Tabel 1. Perbedaan Hasil Analisis

\begin{tabular}{|c|c|}
\hline Sistem Lama & Sistem Baru \\
\hline $\begin{array}{l}\text { Pembeli } \\
\text { membutuhkan } \\
\text { waktu yang lama } \\
\text { untuk memilih } \\
\text { produk }\end{array}$ & $\begin{array}{l}\text { Menggunakan sebuah } \\
\text { sistem untuk } \\
\text { menghemat waktu } \\
\text { dalam memilih produk } \\
\text { dan pembelian }\end{array}$ \\
\hline $\begin{array}{l}\text { Produk kerajinan } \\
\text { di pajang secara } \\
\text { tidak teratur }\end{array}$ & $\begin{array}{l}\text { Data produk di } \\
\text { inputkan ke dalam } \\
\text { sistem dan akan } \\
\text { tersimpan dalam } \\
\text { database, dan gambar } \\
\text { produk ditampilkan di } \\
\text { web }\end{array}$ \\
\hline $\begin{array}{l}\text { Laporan } \\
\text { penjualan masih } \\
\text { dicatat secara } \\
\text { manual }\end{array}$ & $\begin{array}{l}\text { Laporan penjualan } \\
\text { didapat dari data-data } \\
\text { penjualan yang } \\
\text { tersimpan dalam } \\
\text { database } \\
\end{array}$ \\
\hline $\begin{array}{l}\text { Perhitungan total } \\
\text { bayar dilakukan } \\
\text { secara manual }\end{array}$ & $\begin{array}{l}\text { Total pembayaran akan } \\
\text { secara otomatis } \\
\text { dihitung sistem dan } \\
\text { disimpan dalam } \\
\text { database } \\
\end{array}$ \\
\hline
\end{tabular}

Sistem informasi promosi dan penjualan diimplemetasikan pada usaha kerajinan sulaman Indah Mayang. Tahap implementasi merupakan tahap terakhir agar sistem siap dioperasikan. Implementasi antar muka menggambarkan tampilan dari sistem yang dibangun. Berikut ini adalah implementasi antar muka dari sistem informasi promosi dan penjualan pada kerajinan sulaman Indah Mayang:

1. Menu Utama 
Menu utama merupakan menu yang akan keluar pertama kali ketika mengakses sistem. Menu utama ini terdiri dari home, shop, galleri, kontak, serta login dan register untuk pelanggan. Menu utama sistem dapat dilihat pada Gambar 2.
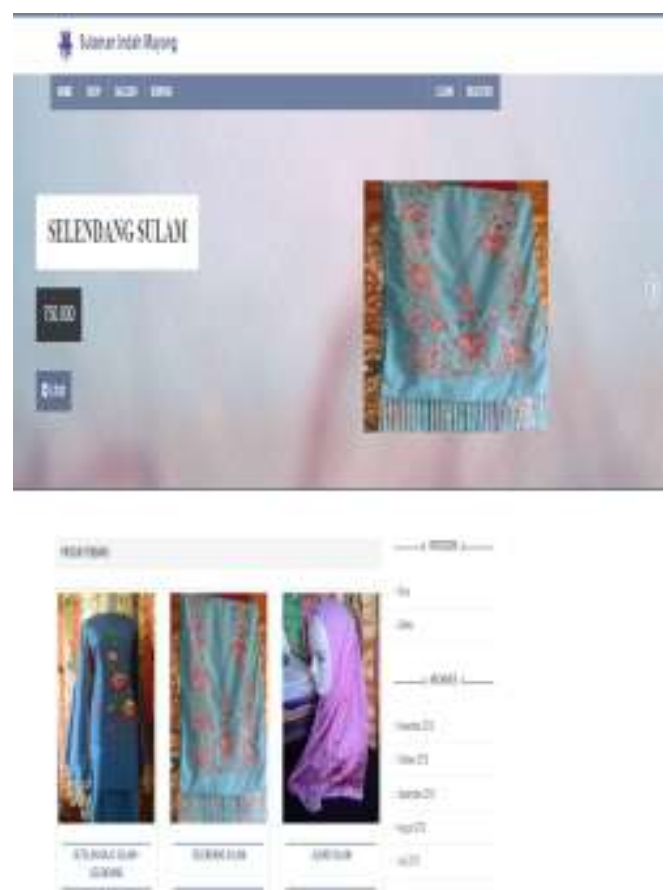

Gambar 2. Menu Utama

a. Menu Utama Admin

Menu utama admin merupakan halaman yang akan keluar pertama kali ketika admin telah melakukan login pada sistem. Menu utama admin ini terdiri dari transaksi, order, member, product, gallery, rekening dan kontak. Menu utama admin dapat dilihat pada Gambar 3.

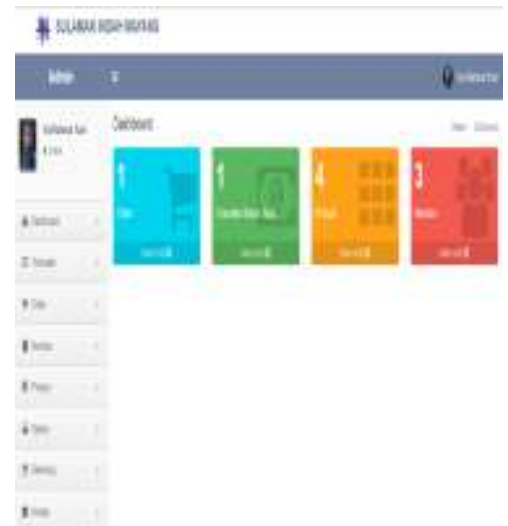

Gambar 3. Menu Utama Admin

\section{Input}

a. Input Data Produk

Form input data produk berfungsi untuk mengentrikan data barang. Pada halaman input data barang terdapat tombol simpan untuk proses penyimpanan data ke dalam database dan tombol data produk untuk melihat semua data produk. Form data produk dapat dilihat pada Gambar 4.

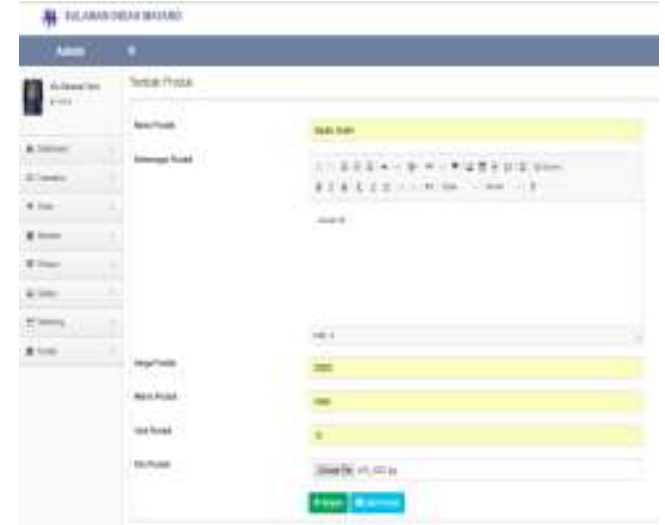

Gambar 4. Form Data Produk b. Input Data Registrasi Konsumen Halaman registrasi konsumen berfungsi untuk konsumen mendaftar sebagai member agar dapat melakukan login ke sistem dan melakukan transaksi secara online. Tampilan form registrasi konsumen dapat dilihat pada Gambar 5.

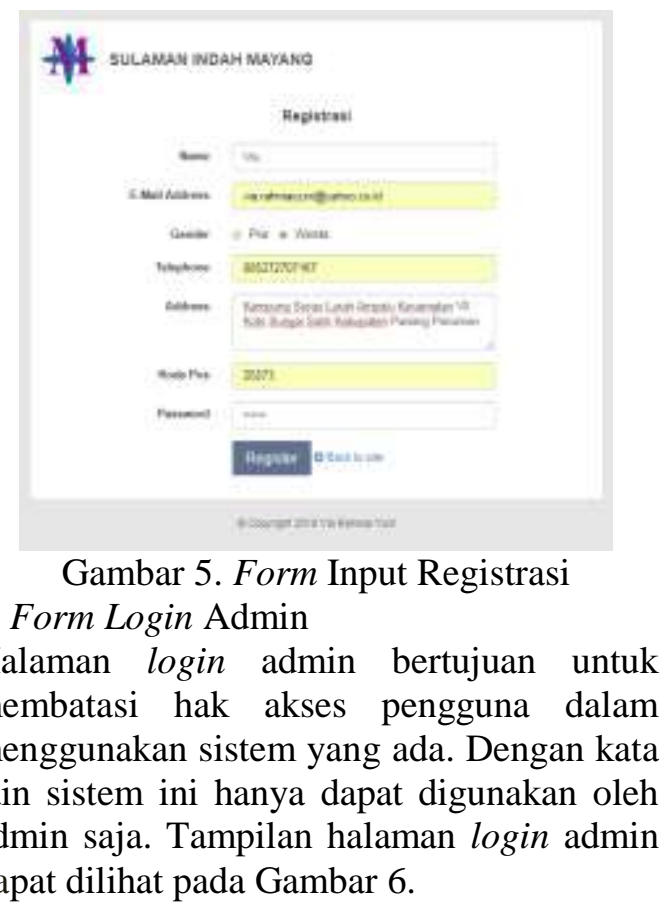




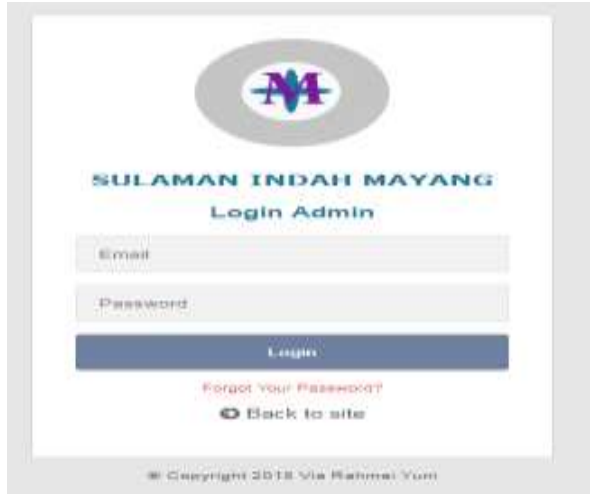

Gambar 6. Form Login Admin

\section{d. Form Login Member}

Halaman login member bertujuan untuk membatasi hak akses pengguna dalam menggunakan sistem yang ada. Dengan kata lain sistem ini hanya dapat digunakan oleh member yang telah mendaftar. Tampilan halaman login member dapat dilihat pada Gambar7.

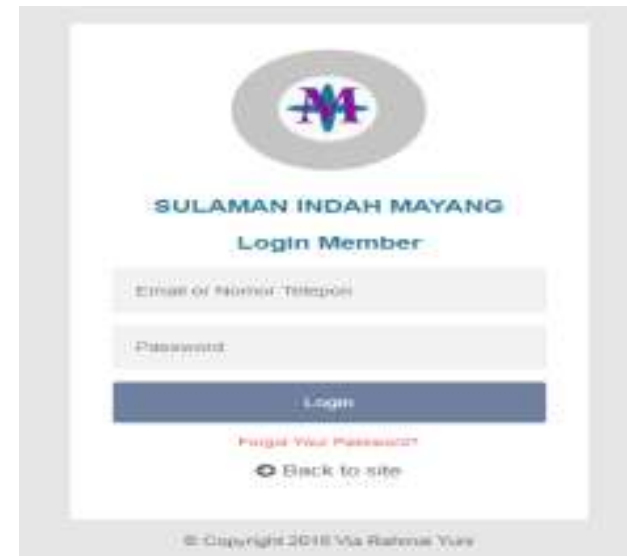

Gambar 7. Form Login Member e. Input Galeri

Form input data galeri berfungsi untuk mengentrikan data galeri berupa foto-foto. Pada halaman input galeri terdapat tombol simpan untuk proses penyimpanan data kedalam database dan tombol data galeri untuk melihat semua data galeri. Form data produk dapat dilihat pada Gambar 8.

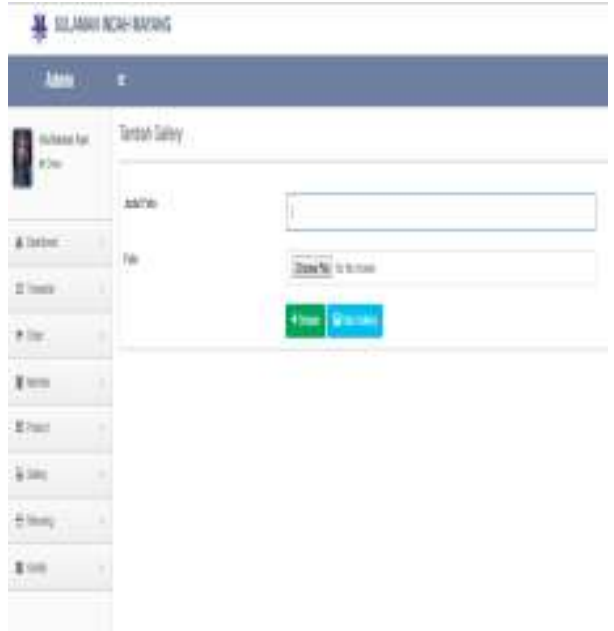

Gambar 8. Form Input Gallery

f. Konfirmasi Pembayaran

Konfirmasi pembayaran berfungsi untuk melakukan check out pembelian, mengkonfirmasi pembayaran yang telah dilakukan pembeli. Form konfirmasi pembayaran dapat dilihat pada Gambar 9.

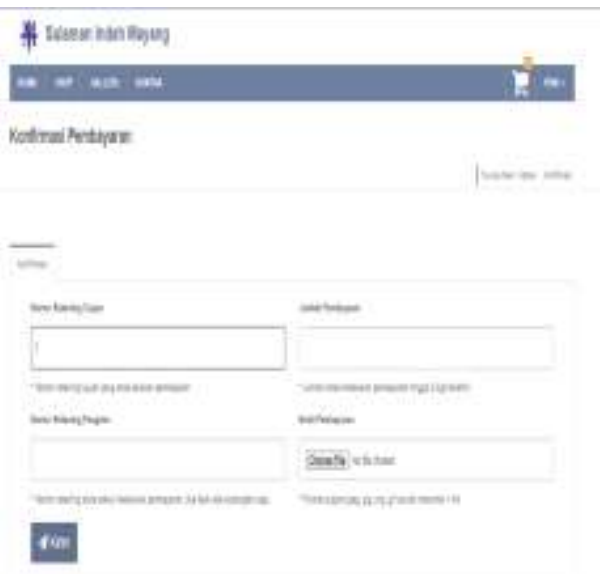

Gambar 9. Form Konfirmasi Pembayaran 3. Proses

a. Konfirmasi Pemesanan

Konfirmasi pemesanan berfungsi untuk mengkonfirmasi pesanan, dan membatalkan pesanan pelanggan. Form konfirmasi pemesanan dapat dilihat pada Gambar 10. 


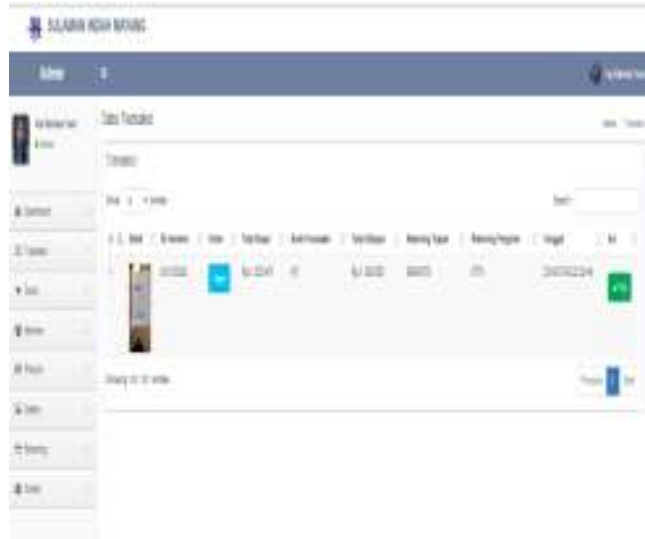

Gambar 10. Form Konfirmasi Pemesanan

b. Proses Order

Proses order berfungsi untuk merubah status pesanan pelanggan. Form ubah status order dapat dilihat pada Gambar 11.

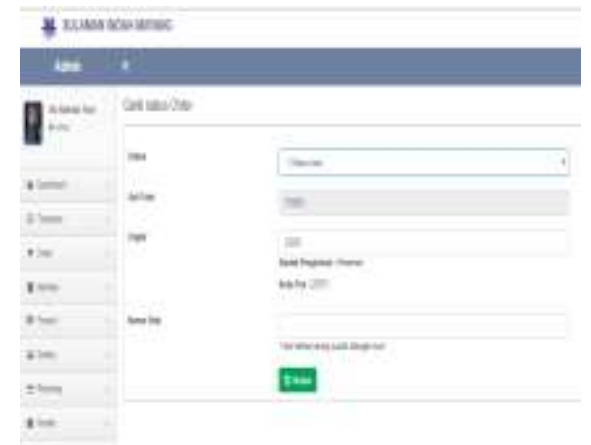

Gambar 11. Form Proses Order

4. Output

a. Faktur Pembelian

Faktur pembelian berisi detail pembelian barang yang dilakukan oleh pembeli. Faktur pembelian dapat dilihat pada Gambar 12.

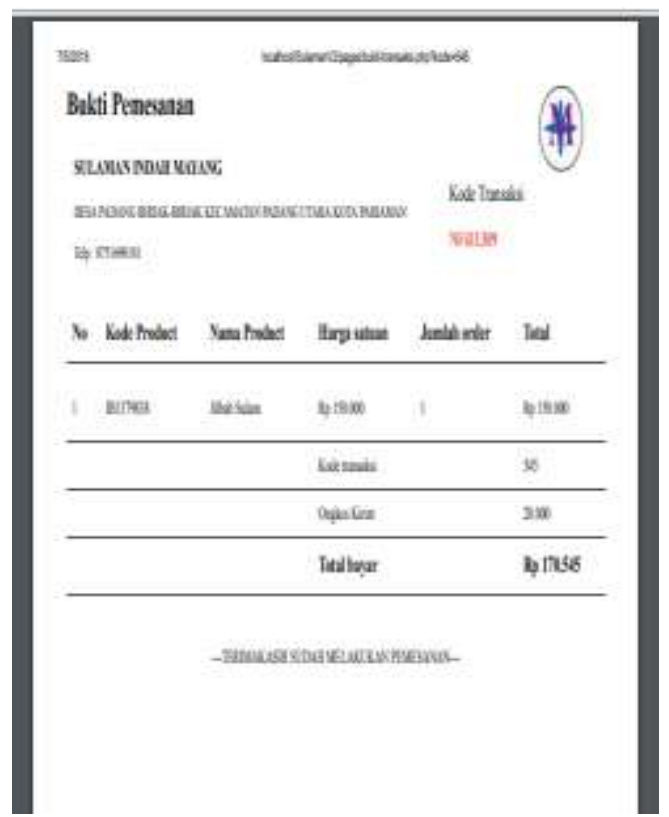

Gambar 12. Faktur Pembelian

b. Laporan Data Produk

Laporan data produk berisi data-data produk kerajinan sulaman. Laporan data produk dapat dilihat pada Gambar 13.

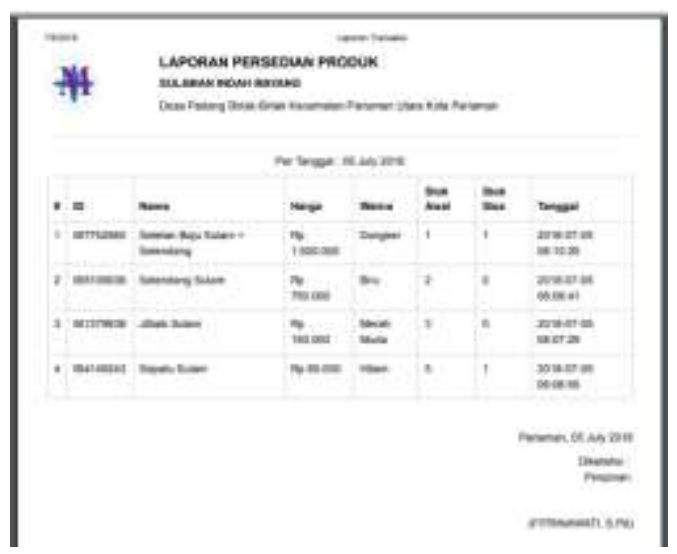

Gambar 13. Laporan Data Produk c. Laporan Transaksi Penjualan Laporan penjualan berisi daftar penjualan dalam kurun waktu tertentu. Laporan penjualan dapat dilihat pada Gambar 14. 


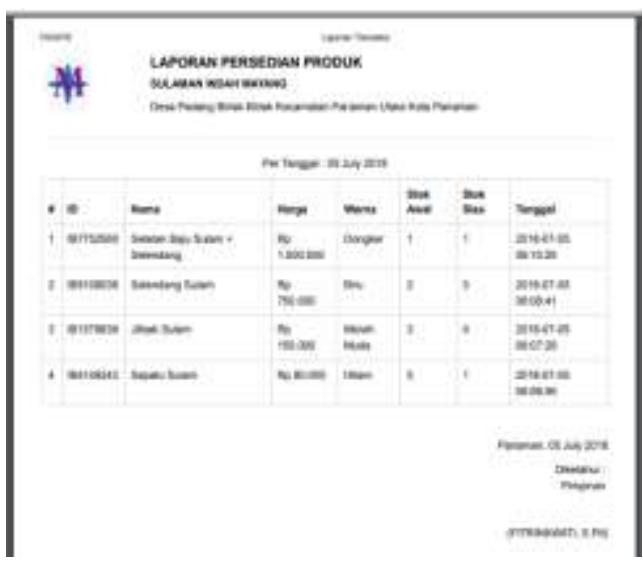

Gambar 14. Laporan Transaksi Penjualan

\section{PENUTUP}

Berdasarkan hasil pembahasan pada Sistem Informasi Promosi dan Penjualan Kerajinan Sulaman Berbasis Web pada Sulaman Indah Mayang Pariaman, maka dapat disimpulkan bahwa sistem yang dirancang dapat mendukung proses promosi dan penjualan kerajinan sulaman secara praktis dan efisien. Pihak penjual dapat dengan mudah mempromosikan produk. Pembeli dapat melihat produk-produk yang ditawarkan, dan pembeli dapat memesan barang yang diinginkan dengan menggunakan sistem yang dirancang. Dapat membantu dalam proses pembuatan laporan yang cepat dan akurat, data penjualan akan tersimpan secara otomatis dalam database, sehingga tidak ada lagi kemungkinan data tidak tercatat dan hilang.

\section{UCAPAN TERIMA KASIH}

Penelitian ini dapat terlaksana dengan bantuan berbagai pihak, untuk itu diucapkan terima kasih kepada Yayasan Amal Bakti Mukmin Padang, STMIK Indonesia Padang, Lembaga LPPM STMIK Indonesia Padang dan Pimpinan Usaha Kerajinan Sulaman Indah Mayang Pariaman.

\section{DAFTAR PUSTAKA}

[1] S. Informasi, P. Digital, J. Sistem, I. Fakultas, I. Komputer, and U. Sriwijaya, "Pdngembangan Model Sistem Informasi Perpustakaan Dengan Teknologi Informasi Berbasis Wireless Aplikacation Protocol (WAP) Pada Universtas Sriwijaya," J. Sist. Inf. (JSI), vol. 4, no. 1, pp. 425-436, 2012.

[2] D. Metode, S. Studi, P. T. Chingmix, and B. Sejahtera, "Strategi Pengembangan Teknologi ECommerce," J. Telemat. MKOM, Vol.3 No.2, Sept. 2011, vol. 3, no. 2, 2011.

[3] T. Chandrayanti and A. Mulyana, "Model Pengembangan Usaha Kecil Menengah (UKM) Kreatif di Sumatera Barat dengan Pendekatan Terintegrasi Zaman Now," Pros. 4th Semin. Nas. dan Call Pap. 2018 Fak. Ekon. Univ. Muhammadiyah Jember Hal 59-7, pp. 59-70, 2018.

[4] S. Haryanti and T. Irianto, "Rancang Bangun Sistem Informasi E-Commerce Untuk Usaha Fashion Studi Kasus Omah Mode Kudus," J. Speed - Sentra Penelit. Eng. dan Edukasi, vol. 3, no. 1, pp. 8-14, 2011.

[5] S. Supriyanto and O. Anggraini, "Penguatan Kapasitas Usaha Perikanan dalam Pengembangan E-commerce di Kabupaten Bantul," Proceeding Community Dev., vol. 1, no. 2017, p. 173, 2018.

[6] A. Umar, "Peranan Media Sosial Sebagai Sarana Promosi Bagi Usaha Kecil dan Menengah," KNIT-2 Nusa Mandiri, vol. 2, no. 1, pp. 29-36, 2016.

[7] I. G. M. Karmawan, "Dampak Peningkatan Kepuasan Pelanggan dalam Proses Bisnis E-Commerce pada Perusahaan Amazon.Com," ComTech Comput. Math. Eng. Appl., vol. 5, no. 2, p. 748, 2017.

[8] A. Aryanto and T. I. Tjendrowasono, "Pemanfaatan Blackberry Sebagai Sarana Komunikasi Dan Penjualan Batik Online Dengan Sistem Dropship Di Batik Solo 85," Journal, Speed Eng. Sentra Penelit., vol. 11, no. 4, pp. 3340, 2014.

[9] E. Haryanto et al., "Kualitas Layanan, Fasilitas Dan Harga Pengaruhnya Terhadap Kepuasan Jasa Layanan Pada Kantor Samsat Manado," J. EMBA, vol. 1, no. 3, pp. 750-760, 2013.

[10] F. Reza, "Strategi promosi penjualan," J. Kaji. Komun., vol. 4, no. 1, pp. 6474, 2016.

[11] S. Informasi and S. I. Padang, "Sistem Pendukung Keputusan Mutasi Karyawan Pada PT. Sakato Jaya Dengan Metode Multi Faktor 
Evaluation Proses," Rang Tek. J., vol. 2, no. 1, pp. 9-15, 2019.

Hasil plagiarism

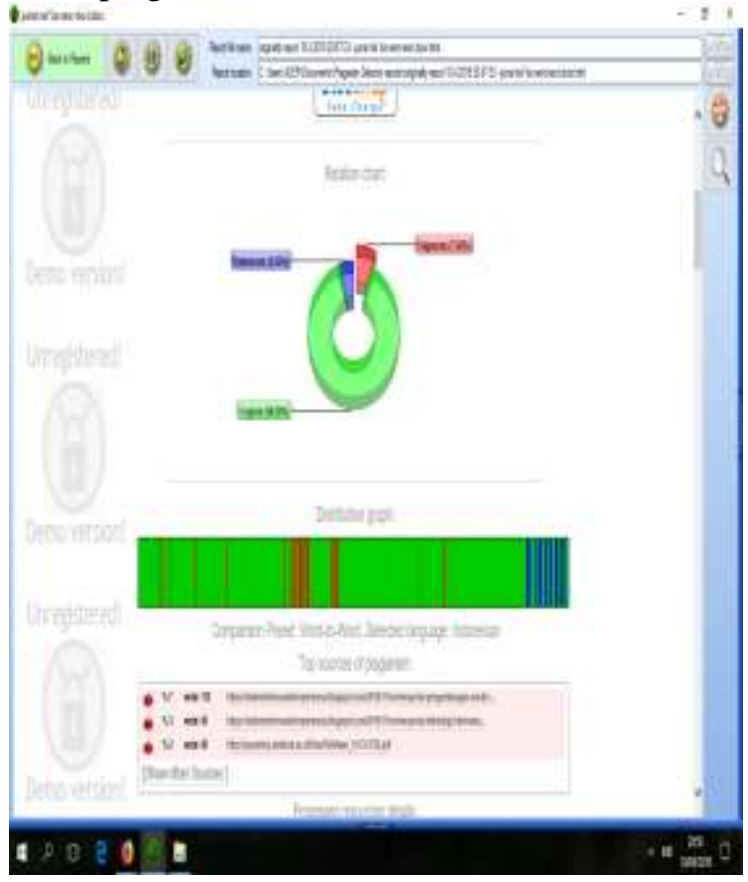

